\title{
Do prostatectomy suitable for localized prostate cancer patient: evidence from meta-analysis
}

\section{Xiaojin Luo}

people's hospital of yichun city

Meilian Yi

people's hoapital of yichun city

Qun Hu

people's hospital of yichun city

Weihua Yin ( $\nabla$ haogeqiu@163.com )

people's hospital of yichun city

Research article

Keywords: prostatectomy; observation; prostate cancer; survival; erection dysfunction.

Posted Date: July 30th, 2019

DOI: https://doi.org/10.21203/rs.2.12155/v1

License: (c) (1) This work is licensed under a Creative Commons Attribution 4.0 International License.

Read Full License 


\section{Abstract}

Objective:To evaluate the role of prostatectomy for localized prostate cancer patient. Methods: A systematic search was conducted using PubMed, and Web of Science through March 22, 2019 according to Preferred Reporting Items for Systematic Reviews and Meta-analyses guidelines to identify studies reporting on prostatectomy for localized prostate cancer patient. Results: Of a total of 1827 studies, 6 were considered for evidence synthesis. A total of 4476 patients in 4 studies were included for survival analysis, 2,779 patients received prostatectomy and 1,697 patients were received no treatment but regularly followed up. Two other studies were included for adverse effects analysis. Prostatectomy displayed a significantly decreased risk of death of $35 \%$ compared with observation $(O R=0.65,95 \% \mathrm{Cl}$ $0.53-0.81, P<0.0001)$. Pooled data indicated prostatectomy reduced $55 \%$ risk of disease progression $(\mathrm{OR}=0.45,95 \% \mathrm{Cl} 0.34-0.60, \mathrm{P}<0.00001)$. Anxiety, depressed mode, wellbeing, and sense of meaningfulness for patients were no difference between prostatectomy and observation group. However, prostatectomy increased 2.77 folds risk of erection dysfunction $(\mathrm{OR}=2.77,95 \% \mathrm{Cl}, 1.60-4.81, \mathrm{P}=0.0003$ Conclusion: Prostatectomy prolonged survival and deferred disease progression compared to observation for localized prostate cancer patients. Symptoms between two groups were not significant difference except for erection function. Patients should decide prostatectomy or not after balancing the survival benefit and erection dysfunction.

\section{Background}

It was estimated 174,650 new prostate cancer cases and 31,620 deaths in United States in 2019, prostate cancer was expected to be the first place of new cancer cases, and second cause of deaths in men [1]. Treatment of prostate cancer included active surveillance, chemotherapy, radiation therapy, endocrine therapy, radical prostatectomy, and etc. ${ }^{22]}$. Radiation therapy was preferred by oncologist, whereas, radical prostatectomy was usually performed by urologist. Controversial management was existing for localized prostate cancer patients. Guidelines emphasized the role of observation focused on serial serum PSA measurements, digital rectal examinations and recurrence prostate biopsies to check for and identify pathological indications of tumor progression ${ }^{[3]}$. It is meaningful to determine whether prostatectomy or observation was suitable for localized prostate cancer patient.

Several studies compared prostatectomy and observation for localized prostate cancer patient, but received conflict results ${ }^{[4-7]}$. Hamdy et al. ${ }^{[6]}$ randomized 545 localized prostate cancer patients received active monitoring, and 553 patients received surgery between 1999 and 2009. The prostate-cancer mortality was assessed at a median of 10 years of follow-up. There were 13 prostate-cancer-specific deaths overall: 8 in the active-monitoring group (1.5 deaths per 1000 person-years), 5 in the surgery group (0.9 per 1000 person-years). But no significant difference was seen among the groups. Another research performed by Wilt et al. ${ }^{[7]}$ randomly assigned 731 men with localized prostate cancer to radical prostatectomy or observation from 1994 to 2002, after nearly 20 years of follow-up, they concluded that surgery was not associated with significantly lower mortality than observation, however, surgery was 
associated with a higher frequency of adverse events than observation. Recently, Bill-Axelson ${ }^{[5]}$ reported a 29-year follow-up results about localized prostate cancer patients received radical prostatectomy or observation, patients received surgery gained a mean of 2.9 years of life. We conducted this metaanalysis to compare the survival benefit and quality of life between prostatectomy and observation.

\section{Methods}

\section{Search Strategy}

The meta-analysis and systemic review were performed by searching the Web of Science and PubMed through March 22, 2019. Additional records identified through other sources (by screening the reference in the identified studies). Searches included the terms "localized prostate cancer" OR "early prostate cancer" AND "observation" OR "active surveillance" OR "watchful waiting" AND "prostatectomy". The citation in the retrieved articles were reviewed to identify other potentially relevant studies.

Inclusion and exclusion criteria

Two investigators (Xiaojin Luo and Weihua Yin) independently extracted the data, and an agreement was reached by discussion. Studies that met the following criteria were included in this meta-analysis: (1) all patients were pathologically diagnosed with localized prostate cancer; (2) patients were regularly followed up; (3) sufficient data were available for examining cancer specific survival and the hazard ratio (HR) with its $95 \%$ confidence interval $(95 \% \mathrm{Cl})$. Major reasons for exclusion of studies were: (1) patients had cancer metastases or prostate membrane infiltration; (2) incomplete data for the analysis; (3) conference abstracts, reviews, letters to editors/commentaries/editorials, and articles published in a language that cannot be translated; and (4) duplicate data (these were removed and only the updated data were selected).

\section{Data extraction}

Author, publication year, patient number, adverse effect, risk ratio or hazard ratios and upper confidence interval ( $\mathrm{UCl})$ and lower confidence interval ( $\mathrm{LCl}$ ) of each comparison were collected from the included publication. The main adverse effects included difficulties with erection, anxiety, depressed mood, wellbeing, quality of life, sense of meaningfulness, urinary function bother.

\section{Statistical analysis}

The HR with its $95 \% \mathrm{Cl}$ was extracted from the included studies. The heterogeneity in the studies was evaluated using $I^{2}$ statistics (value ranged from 0 to $100 \%$ ). We pooled the information with a random or fixed effect model according to the $\mathrm{I}^{2}$ value. The fixed effects model method was used when $\mathrm{I}^{2}<50 \%$, indicating no heterogeneity among studies. When the existence of heterogeneity was indicated, the random effects model was applied. The publication bias was evaluated. Sensitivity analysis was 
performed to assess the stability of the results. Funnel plots were drawn to estimate publication bias, whether the funnel plot was symmetrical was assessed with the Egger's test. When using Egger's test to assess the publication bias, $\mathrm{P}<0.05$ statistically indicated publication bias ${ }^{[8]}$. The statistical analysis was performed by using Review Manager Software (version 3.6).

\section{Results}

Study selection and characteristics

1,827 relevant studies were identified through the literature search. After excluding 1,628 articles focused on benign prostate cancer, advanced prostate cancer and so on, 48 articles were full-text assessed. We noted that included researches were screened carefully, many researches were duplicated data and only the updated data were selected, such as research conducted by Wilt ${ }^{[7,9-13]}$ and Bill-Axelson ${ }^{[5,14-18]}$. Finally, 6 studies met the inclusion criteria were included in our meta-analysis ${ }^{[4-7,14,19]}$ (Figure 1). Of these, 4 studies with total of 4,476 patients were included for survival analysis ${ }^{[4-7]}$. 2,779 patients received prostatectomy and 1,697 patients were received no treatment but regularly followed up. Two other studies were included for adverse effects analysis ${ }^{[14,19]}$. Quality of life were assessed by Scandinavian Prostate Cancer Group Study Number 4 (SPCG-4) investigators in a study, 136 men in the radical prostatectomy group, 136 men in the watchful-waiting group answered the questionnaire ${ }^{[14]}$. In another study, 545 patients were active monitoring and 553 received radical prostatectomy, patientreported outcomes were measured in the Prostate Testing for Cancer and Treatment (ProtecT) trial ${ }^{[19]}$.

\section{Prostate cancer specific survival}

Of the 4 studies, 2 studies with 2,647 patients indicated a better prognosis associated with surgery compared to surveillance. These included 1,870 patients received prostatectomy and 777 patients with observation ${ }^{[4,5]}$. Another two studies with 1,829 patients showed that no meaningful differences existed between prostatectomy and observation. These included 909 patients received prostatectomy and 920 patients with observation ${ }^{[6,7]}$. In our meta-analysis, $I^{2}$ was $20 \%$, therefore, the fixed effect model was used for the analysis, and the pooled odds ratio (OR) was 0.65 ( $95 \% \mathrm{Cl} 0.53-0.81, \mathrm{P}<0.0001)$. Thus, prostatectomy displayed a significantly decreased risk of death of $35 \%$ compared with observation (Figure 2).

\section{Disease progression}

Tumor progression was defined as palpable extracapsular extension or voiding obstruction that required intervention ${ }^{[5]}$, distant metastases were also considered progression. Two researches with 900 patients received surgery and 893 patients with observation were analyzed in our meta-analysis ${ }^{[5,6]}$. The fixed 
effect model was used as $\mathrm{I}^{2}$ was $0 \%$. Pooled data indicated prostatectomy reduced $55 \%$ risk of disease progression $(\mathrm{OR}=0.45,95 \% \mathrm{Cl} 0.34-0.60, \mathrm{P}<0.00001$, Figure 3$)$.

Patient-reported symptoms

Posttreatment symptoms distress are important considerations in determining whether surgery is the most appropriate course of treatment in patients with localized prostate cancer. Patient-reported symptoms was measured in four studies ${ }^{[4,7,14,19]}$. We concluded the symptoms results from several aspects including emotion, sex function, and urinary function.

Anxiety

Two studies compared 601 patients received prostatectomy with 594 patients received observation [14, ${ }^{19]}$. Anxiety $(\mathrm{OR}=0.60,95 \% \mathrm{Cl}, 0.38-0.96)$ was less common among men treated with prostatectomy compared to observation in one study ${ }^{[14]}$. Another study indicated anxiety was similar incident for patients received prostatectomy or observation ${ }^{[19]}$. Pooled data showed anxiety was no difference between prostatectomy and observation group $(\mathrm{OR}=0.73,95 \% \mathrm{Cl}, 0.39-1.40, \mathrm{P}=0.35$, Figure 4).

Depressed mood

595 patients received prostatectomy and 600 patients received observation were measured for depressed questionnaire in two studies ${ }^{[14,19]} .72$ patients received prostatectomy and 77 patients received observation suffered from depressed trouble, no statistical significance was found between the populations ( $\mathrm{OR}=0.93,95 \% \mathrm{Cl}, 0.66-1.32, \mathrm{P}=0.69$, Figure 4$)$.

Wellbeing and sense of meaningfulness

Bill-Axelson evaluated the wellbeing and sense of meaningfulness for patients ${ }^{[14]}$, surgery did not influence these two kinds of emotion (Figure 4).

Quality of life

Two studies compared quality of life in 522 patients received prostatectomy with 530 patients received observation ${ }^{[14,19]} 110$ patients in prostatectomy group and 109 patients in observation group complained low quality of life, there was no significant difference $(\mathrm{OR}=1.03,95 \% \mathrm{Cl}, 0.76-1.39, \mathrm{P}=0.84$, Figure 4).

Difficulties with erection

Four studies evaluated the function of erection $[4,7,14,19]$. 919 of the 2,480 men in the prostatectomy group and 305 of the 1,369 men in the observation group had difficulties with erection. Our analysis 
indicated surgery increased 2.77 folds risk of erection dysfunction $(\mathrm{OR}=2.77,95 \% \mathrm{Cl}, 1.60-4.81$, $\mathrm{P}=0.0003$, Figure 4).

Urinary function bother

Incontinence was the main urinary function bother, three studies with 2,342 men in the prostatectomy group and 1,260 men in the observation group were followed up for urinary function ${ }^{[4,7,19]}$. Surgery did not influence urinary function $(\mathrm{OR}=1.61,95 \% \mathrm{Cl}, 0.57-4.52, \mathrm{P}=0.36$, Figure 4$)$.

The quality of evidence

Risk of bias were assessed for included studies. Only one study cannot be assigned as high quality of evidence ${ }^{[6]}$. We then excluded the study to conducted meta-analysis again, and found prostatectomy decreased a risk of death of $35 \%$ compared with observation $(\mathrm{OR}=0.65,95 \% \mathrm{Cl}, 0.52-0.81, \mathrm{P}=0.0001$, supplement figure 1).

Publication bias

Egger's test and Begg's funnel plots were used to assess the publication bias in this meta-analysis. Egger's funnel plot test $(P=0.348)$ verified that there was no publication bias among the included studies, also, the Begg's test ( $P=1.00$; Figure 5$)$ did support this conclusion.

Sensitivity analysis

Studies were sequentially removed to investigate whether any study could have an influence on the pooled results (Figure 6). The test suggested that the pooled result did not exhibit alterations when an individual study was excluded.

\section{Discussion}

In this meta-analysis, we included 6 studies investigated the survival and symptoms for localized prostate cancer patients. Four studies with a total of 4,476 patients were included for prostate cancer specific survival analysis, 317 of the 2,779 men in the prostatectomy group and 375 of the 1,697 men in the observation group had died of prostate cancer. Two studies compared the disease progression between the groups. 105 of the 900 men in the prostatectomy group and 183 of the 893 men in the observation group had cancer progression. Our meta-analysis indicated prostatectomy contributed to prolong survival and defer disease progression. We noted a study in which follow up was 3 years ${ }^{[4]}$, one was 10 years ${ }^{[6]}$, and other two were 19.5 and 29 years ${ }^{[5,7]}$. Most patients survive within 10 years follow 
up despite in prostatectomy group or observation group, the effects of prostatectomy may not exhibit. The 5-year overall survival rate and no biological evidence of disease rate for localized prostate cancer patients were $97.7 \%$ and $92.4 \%$, respectively ${ }^{[20]}$. Thus, enough time for follow up was necessary to compare the prostatectomy group and observation group. We assessed the quality of evidence in the meta-analysis, and found the study in which patients was 3 year follow up may lead to bias of the result. After excluded the study, meta-analysis was performed, similar results that prostatectomy decreased risk of death was received (supplement figure 1).

The incidental discovery of low-grade prostate cancer patients are not likely to shorten survival or cause health problems during his lifetime ${ }^{[21]}$, guidelines on the use of observation or active surveillance in men with clinically insignificant prostate cancer were described ${ }^{[22-24]}$. Risk stratification for localized prostate cancer patients was necessary. In our research, due to the lack of sufficient data, subgroup analysis was not performed. Patients should stratify according to age, PSA value, Gleason score and so on. Included studies evaluated patients age $<65$ or $\geq 65$ years old, death from prostate cancer was deceased in prostatectomy group in one study ${ }^{[5]}$, another study did not support this results [7], PSA value or Gleason score did not affect the results in the study that surgery was not associated with significantly lower prostate-cancer mortality than observation ${ }^{[7]}$. Currently, overtreatment is a well-recognized consequence of the diagnosis of low risk prostate cancer, who are at a low risk of aggressive or lethal disease ${ }^{[24,25]}$. It was needed that more randomize studies to research the role of prostatectomy in low, intermediate, or high-risk prostate cancer patients.

Our meta-analysis indicated prostatectomy would benefit for localized prostate cancer patient's survival, but the adverse effects were existing. Anxiety, depressed mode, wellbeing, and sense of meaningfulness for patients were no difference between prostatectomy and observation group (Figure 4). Erection function and urination control were the main concerns for clinicians and patients ${ }^{[26-28]}$. We found erection dysfunction was more common in prostatectomy group, urinary symptoms were similar between prostatectomy group and observation group (Figure 4). It was noted that the prostatectomy performed in included studies were many years ago, the techniques for nerve- sparing were insufficient ${ }^{[29-31]}$. The management for erectile dysfunction post-radical prostatectomy was multiple ${ }^{[32]}$. Thus, it was significant to compared prostatectomy (which applied new nerve-sparing theory and techniques) with observation for localized prostate cancer in new era.

High quality of included studies ensured robust results of our meta-analysis, so far, our research concluded the available data and found prostatectomy prolong survival for localized prostate cancer patients without obvious adverse effects but erection dysfunction. The benefit and impairment of prostatectomy should inform the patients to let them decide prostatectomy or not.

\section{Conclusions}


Our research indicated prostatectomy prolonged survival and deferred disease progression compared to observation for localized prostate cancer patients. Symptoms between two groups were not significant difference except for erection function. Patients should decide prostatectomy or not after balancing the survival benefit and erection dysfunction.

\section{Abbreviations}

HR: hazard ratio; UCl: upper confidence interval; LCl: lower confidence interval; SPCG-4: Scandinavian Prostate Cancer Group Study Number 4.

\section{Declarations}

- Ethics approval and consent to participate: Not applicable.

- Consent to publish: Not applicable.

- Availability of data and materials: Not applicable.

- Competing interests (rename 'Conflict of interests' to 'Competing interests') : Not applicable.

- Funding: None.

- Authors' Contributions: Project development: Weihua Yin; Data collection or management: Xiaojin Luo; Data analysis and Interpretation: Meilian Yi, Qun Hu; Manuscript writing: Xiaojin Luo; Manuscript editing: Weihua Yin; Study Supervision: Weihua Yin. All authors have read and approved the manuscript.

- Acknowledgements: None.

\section{References}

1. Siegel RL, Miller KD, Jemal A. Cancer statistics, 2019. CA Cancer J Clin 2019, 69(1): 7-34.

2. Sanda MG, Cadeddu JA, Kirkby E, Chen RC, Crispino T, Fontanarosa J, Freedland SJ, Greene K, Klotz LH, Makarov DV, Nelson JB, Rodrigues G, Sandler HM, Taplin ME, Treadwell JR. Clinically Localized Prostate Cancer: AUA/ASTRO/SUO Guideline. Part II: Recommended Approaches and Details of Specific Care Options. The Journal of urology 2018, 199(4): 990-997.

3. Bruinsma SM, Bangma CH, Carroll PR, Leapman MS, Rannikko A, Petrides N, Weerakoon M, Bokhorst LP, Roobol MJ, Movember GAPc. Active surveillance for prostate cancer: a narrative review of clinical guidelines. Nat Rev Urol 2016, 13(3): 151-167.

4. Barocas DA, Alvarez J, Resnick MJ, Koyama T, Hoffman KE, Tyson MD, Conwill R, McCollum D, Cooperberg MR, Goodman M, Greenfield S, Hamilton AS, Hashibe M, Kaplan SH, Paddock LE, Stroup AM, Wu XC, Penson DF. Association Between Radiation Therapy, Surgery, or Observation for 
Localized Prostate Cancer and Patient-Reported Outcomes After 3 Years. JAMA 2017, 317(11): 11261140 .

5. Bill-Axelson A, Holmberg L, Garmo H, Taari K, Busch C, Nordling S, Haggman M, Andersson SO, Andren O, Steineck G, Adami HO, Johansson JE. Radical Prostatectomy or Watchful Waiting in Prostate Cancer - 29-Year Follow-up. N Engl J Med 2018, 379(24): 2319-2329.

6. Hamdy FC, Donovan JL, Lane JA, Mason M, Metcalfe C, Holding P, Davis M, Peters TJ, Turner EL, Martin RM, Oxley J, Robinson M, Staffurth J, Walsh E, Bollina P, Catto J, Doble A, Doherty A, Gillatt D, Kockelbergh R, Kynaston H, Paul A, Powell P, Prescott S, Rosario DJ, Rowe E, Neal DE. 10-Year Outcomes after Monitoring, Surgery, or Radiotherapy for Localized Prostate Cancer. N Engl J Med 2016, 375(15): 1415-1424.

7. Wilt TJ, Jones KM, Barry MJ, Andriole GL, Culkin D, Wheeler T, Aronson WJ, Brawer MK. Follow-up of Prostatectomy versus Observation for Early Prostate Cancer. N Engl J Med 2017, 377(2): 132-142.

8. Chen Q, Li L, Wang G, Hu J, Sun T, Fu B. Do histological variants in urothelial carcinoma of the bladder portend poor prognosis? A systematic review and meta-analysis. Oncotarget 2017, 8(29): 48263-48271.

9. Wilt TJ. The Prostate Cancer Intervention Versus Observation Trial: VA/NCl/AHRQ Cooperative Studies Program \#407 (PIVOT): design and baseline results of a randomized controlled trial comparing radical prostatectomy with watchful waiting for men with clinically localized prostate cancer. Journal of the National Cancer Institute Monographs 2012, 2012(45): 184-190.

10. Wilt TJ, Brawer MK. The Prostate Cancer Intervention Versus Observation Trial: a randomized trial comparing radical prostatectomy versus expectant management for the treatment of clinically localized prostate cancer. The Journal of urology 1994, 152(5 Pt 2): 1910-1914.

11. Wilt TJ, Brawer MK. The Prostate Cancer Intervention Versus Observation Trial (PIVOT). Oncology (Williston Park, NY) 1997, 11(8): 1133-1139; discussion 1139-1140, 1143.

12. Wilt TJ, Brawer MK, Barry MJ, Jones KM, Kwon Y, Gingrich JR, Aronson WJ, Nsouli I, lyer P, Cartagena R, Snider G, Roehrborn C, Fox S. The Prostate cancer Intervention Versus Observation Trial:VA/NCI/AHRQ Cooperative Studies Program \#407 (PIVOT): design and baseline results of a randomized controlled trial comparing radical prostatectomy to watchful waiting for men with clinically localized prostate cancer. Contemporary clinical trials 2009, 30(1): 81-87.

13. Wilt TJ, Brawer MK, Jones KM, Barry MJ, Aronson WJ, Fox S, Gingrich JR, Wei JT, Gilhooly P, Grob BM, Nsouli I, lyer P, Cartagena R, Snider G, Roehrborn C, Sharifi R, Blank W, Pandya P, Andriole GL, Culkin D, Wheeler T. Radical prostatectomy versus observation for localized prostate cancer. N Engl J Med 2012, 367(3): 203-213.

14. Bill-Axelson A, Garmo H, Holmberg L, Johansson JE, Adami HO, Steineck G, Johansson E, Rider JR. Long-term distress after radical prostatectomy versus watchful waiting in prostate cancer: a longitudinal study from the Scandinavian Prostate Cancer Group-4 randomized clinical trial. Eur Urol 2013, 64(6): 920-928. 
15. Bill-Axelson A, Holmberg L, Filen F, Ruutu M, Garmo H, Busch C, Nordling S, Haggman M, Andersson SO, Bratell S, Spangberg A, Palmgren J, Adami HO, Johansson JE. Radical prostatectomy versus watchful waiting in localized prostate cancer: the Scandinavian prostate cancer group-4 randomized trial. Journal of the National Cancer Institute 2008, 100(16): 1144-1154.

16. Bill-Axelson A, Holmberg L, Garmo H, Rider JR, Taari K, Busch C, Nordling S, Haggman M, Andersson SO, Spangberg A, Andren O, Palmgren J, Steineck G, Adami HO, Johansson JE. Radical prostatectomy or watchful waiting in early prostate cancer. N Engl J Med 2014, 370(10): $932-942$.

17. Bill-Axelson A, Holmberg L, Ruutu M, Garmo H, Stark JR, Busch C, Nordling S, Haggman M, Andersson SO, Bratell S, Spangberg A, Palmgren J, Steineck G, Adami HO, Johansson JE. Radical prostatectomy versus watchful waiting in early prostate cancer. N Engl J Med 2011, 364(18): 17081717.

18. Bill-Axelson A, Holmberg L, Ruutu M, Haggman M, Andersson SO, Bratell S, Spangberg A, Busch C, Nordling S, Garmo H, Palmgren J, Adami HO, Norlen BJ, Johansson JE. Radical prostatectomy versus watchful waiting in early prostate cancer. N Engl J Med 2005, 352(19): 1977-1984.

19. Donovan JL, Hamdy FC, Lane JA, Mason M, Metcalfe C, Walsh E, Blazeby JM, Peters TJ, Holding P, Bonnington S, Lennon T, Bradshaw L, Cooper D, Herbert P, Howson J, Jones A, Lyons N, Salter E, Thompson P, Tidball S, Blaikie J, Gray C, Bollina P, Catto J, Doble A, Doherty A, Gillatt D, Kockelbergh R, Kynaston H, Paul A, Powell P, Prescott S, Rosario DJ, Rowe E, Davis M, Turner EL, Martin RM, Neal DE. Patient-Reported Outcomes after Monitoring, Surgery, or Radiotherapy for Prostate Cancer. N Engl J Med 2016, 375(15): 1425-1437.

20. Hashimoto Y, Motegi A, Akimoto T, Mitsuhashi N, lizuka J, Tanabe K, Ishii Y, Kono S, Izumi S, Karasawa K. The 5-year outcomes of moderately hypofractionated radiotherapy (66 Gy in 22 fractions, 3 fractions per week) for localized prostate cancer: a retrospective study. International journal of clinical oncology 2018, 23(1): 165-172.

21. Chen RC, Rumble RB, Loblaw DA, Finelli A, Ehdaie B, Cooperberg MR, Morgan SC, Tyldesley S, Haluschak JJ, Tan W, Justman S, Jain S. Active Surveillance for the Management of Localized Prostate Cancer (Cancer Care Ontario Guideline): American Society of Clinical Oncology Clinical Practice Guideline Endorsement. Journal of clinical oncology : official journal of the American Society of Clinical Oncology 2016, 34(18): 2182-2190.

22. Bekelman JE, Rumble RB, Chen RC, Pisansky TM, Finelli A, Feifer A, Nguyen PL, Loblaw DA, Tagawa ST, Gillessen S, Morgan TM, Liu G, Vapiwala N, Haluschak JJ, Stephenson A, Touijer K, Kungel T, Freedland SJ. Clinically Localized Prostate Cancer: ASCO Clinical Practice Guideline Endorsement of an American Urological Association/American Society for Radiation Oncology/Society of Urologic Oncology Guideline. Journal of clinical oncology : official journal of the American Society of Clinical Oncology 2018: JC01800606.

23. Sanda MG, Cadeddu JA, Kirkby E, Chen RC, Crispino T, Fontanarosa J, Freedland SJ, Greene K, Klotz LH, Makarov DV, Nelson JB, Rodrigues G, Sandler HM, Taplin ME, Treadwell JR. Clinically Localized Prostate Cancer: AUA/ASTRO/SUO Guideline. Part I: Risk Stratification, Shared Decision Making, and Care Options. The Journal of urology 2018, 199(3): 683-690. 
24. Zhong W, Smith B, Haghighi K, Mancuso P. Systematic Review of Decision Aids for the Management of Men With Localized Prostate Cancer. Urology 2018, 114: 1-7.

25. Goldberg H, Klaassen Z, Chandrasekar T, Fleshner N. Preventing clinical progression and need for treatment in patients on active surveillance for prostate cancer. Curr Opin Urol 2018, 28(1): 46-54.

26. Huang W, Zhang Y, Shen BH, Wang S, Meng HZ, Jin XD. Outcomes of health-related quality of life after open, laparoscopic, or robot-assisted radical prostatectomy in China. Cancer Manag Res 2019, 11: 899-907.

27. Pillay B, Moon D, Love C, Meyer D, Ferguson E, Crowe H, Howard N, Mann S, Wootten A. Quality of Life, Psychological Functioning, and Treatment Satisfaction of Men Who Have Undergone Penile Prosthesis Surgery Following Robot-Assisted Radical Prostatectomy. The journal of sexual medicine 2017, 14(12): 1612-1620.

28. Spratt DE, Lee JY, Dess RT, Narayana V, Evans C, Liss A, Winfield R, Schipper MJ, Lawrence TS, McLaughlin PW. Vessel-sparing Radiotherapy for Localized Prostate Cancer to Preserve Erectile Function: A Single-arm Phase 2 Trial. Eur Urol 2017, 72(4): 617-624.

29. Rossi MS, Moschini M, Bianchi M, Gandaglia G, Fossati N, Dell'Oglio P, Schiavina R, Brunocilla E, Farina E, Picozzi M, Salonia A, Montorsi F, Briganti A. Erectile Function Recovery After Nerve-Sparing Radical Prostatectomy for Prostate Cancer: Is Back to Baseline Status Enough for Patient Satisfaction? The journal of sexual medicine 2016, 13(4): 669-678.

30. Xu P, Wang YH. [Prevention and treatment of erectile dysfunction after prostatectomy: An update]. Zhonghua nan ke xue = National journal of andrology 2017, 23(7): 656-662.

31. Yumioka T, Honda M, Kimura Y, Yamaguchi N, Iwamoto H, Morizane S, Hikita K, Takenaka A. Influence of multinerve-sparing, robot-assisted radical prostatectomy on the recovery of erection in Japanese patients. Reprod Med Biol 2018, 17(1): 36-43.

32. Saleh A, Abboudi H, Ghazal-Aswad M, Mayer EK, Vale JA. Management of erectile dysfunction postradical prostatectomy. Res Rep Urol 2015, 7: 19-33.

\section{Figure Legends}

Figure 1. Flow diagram of the selection study process.

Figure 2. Meta-analysis and risk of bias of included studies for cancer specific survival.

Figure 3. Meta-analysis of included studies for disease progression.

Figure 4. Meta-analysis of included studies for different symptoms.

Figure 5. Funnel plots of survival analysis.

Figure 6. Sensitivity analysis of the summary OR of survival. 
Supplement figure 1. Meta-analysis of included studies except a study with high risk of bias for cancer specific survival.

\section{Figures}
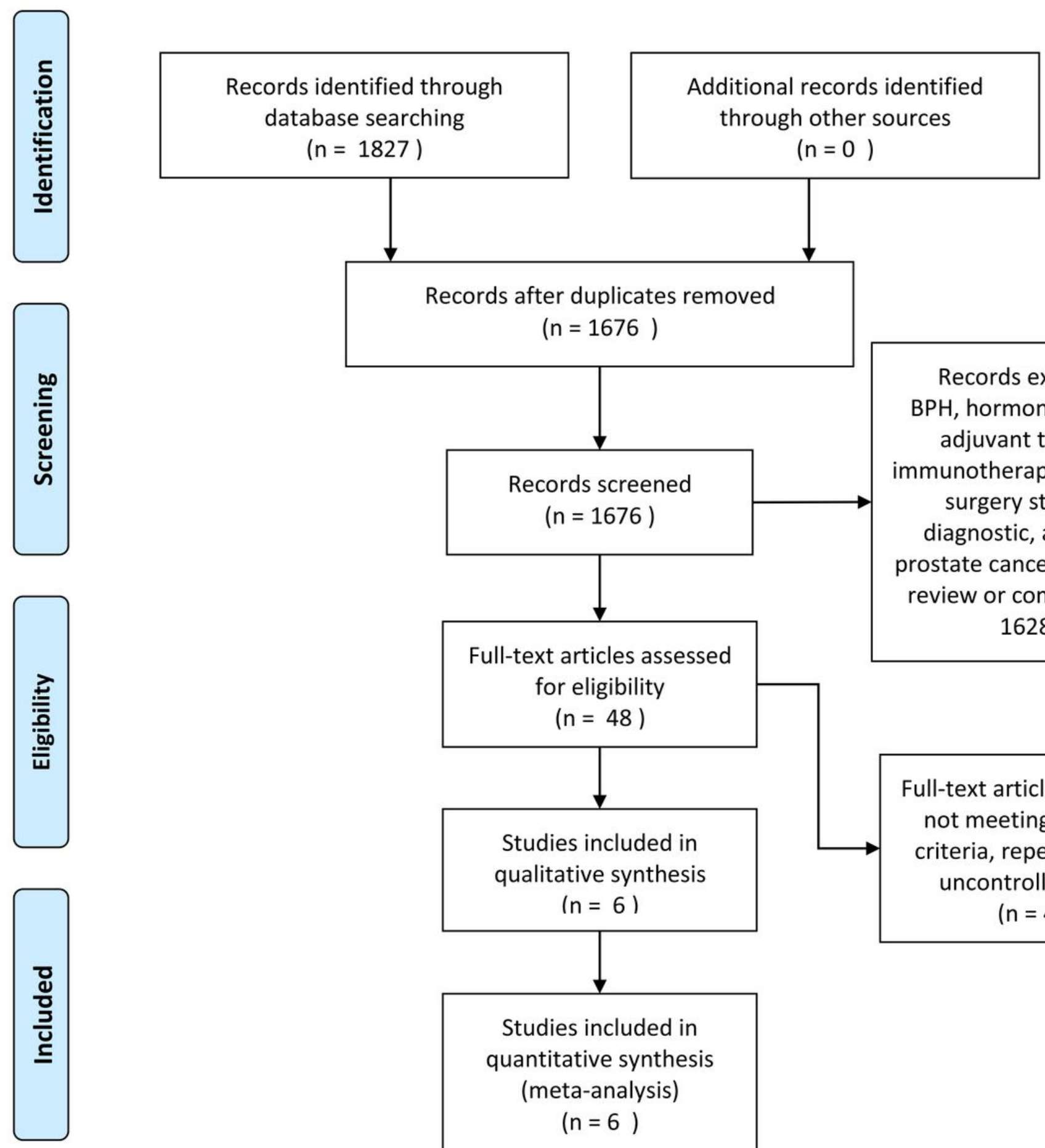

Records excluded, $\mathrm{BPH}$, hormone therapy, adjuvant therapy, immunotherapy, radiation, surgery strategy, diagnostic, advanced prostate cancer, language, review or comment $(\mathrm{n}=$ 1628 )

$$
\begin{aligned}
& \text { Full-text articles assessed } \\
& \text { for eligibility } \\
& (n=48)
\end{aligned}
$$

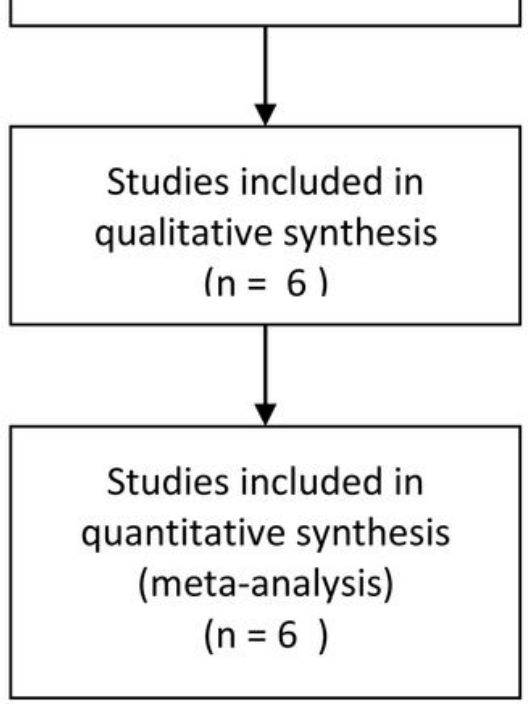

Full-text articles excluded, not meeting including criteria, repeating data, uncontrolled study

$$
(n=42)
$$

\section{Figure 1}

Flow diagram of the selection study process. 


\begin{tabular}{|c|c|c|c|c|c|c|c|c|}
\hline \multirow[b]{2}{*}{ Study or Subgroup } & \multicolumn{2}{|c|}{ Prostatectomy } & \multicolumn{2}{|c|}{ Observation } & \multirow[b]{2}{*}{ Weight } & \multirow{2}{*}{$\begin{array}{l}\text { Odds Ratio } \\
\text { M-H. Fixed. } 95 \% \mathrm{Cl}\end{array}$} & \multirow{2}{*}{$\begin{array}{c}\text { Odds Ratio } \\
\text { M-H. Fixed. } 95 \% \mathrm{Cl}\end{array}$} & Risk of Bias \\
\hline & Events & Total & Events & Total & & & & $A B C D E F G$ \\
\hline Barocas 2017 & 18 & 1523 & 12 & 429 & $8.9 \%$ & $0.42[0.20,0.87]$ & $\longleftarrow$ & \\
\hline Bill-Axelson 2018 & 71 & 347 & 110 & 348 & $42.0 \%$ & $0.56[0.39,0.79]$ & & \\
\hline Hamdy 2016 & 5 & 545 & 8 & 553 & $3.8 \%$ & $0.63[0.21,1.94]$ & & \\
\hline Wilt 2017 & 223 & 364 & 245 & 367 & $45.4 \%$ & $0.79[0.58,1.07]$ & & \\
\hline Total $(95 \% \mathrm{Cl})$ & & 2779 & & 1697 & $100.0 \%$ & $0.65[0.53,0.81]$ & & \\
\hline Total events & 317 & & 375 & & & & & \\
\hline $\begin{array}{l}\text { Heterogeneity: } \mathrm{Chi}^{2}= \\
\text { Test for overall effect: }\end{array}$ & $\begin{array}{l}73, \mathrm{df}=3 \\
=3.93(P\end{array}$ & $\begin{array}{l}=0.29 \\
0.0001\end{array}$ & ; $\left.\right|^{2}=20$ & & & & 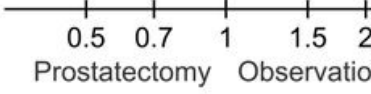 & \\
\hline
\end{tabular}

Risk of bias legend
(A) Random sequence generation (selection bias)
(B) Allocation concealment (selection bias)
(C) Blinding of participants and personnel (performance bias)
(D) Blinding of outcome assessment (detection bias)
(E) Incomplete outcome data (attrition bias)
(F) Selective reporting (reporting bias)
(G) Other bias

\section{Figure 2}

Meta-analysis and risk of bias of included studies for cancer specific survival.

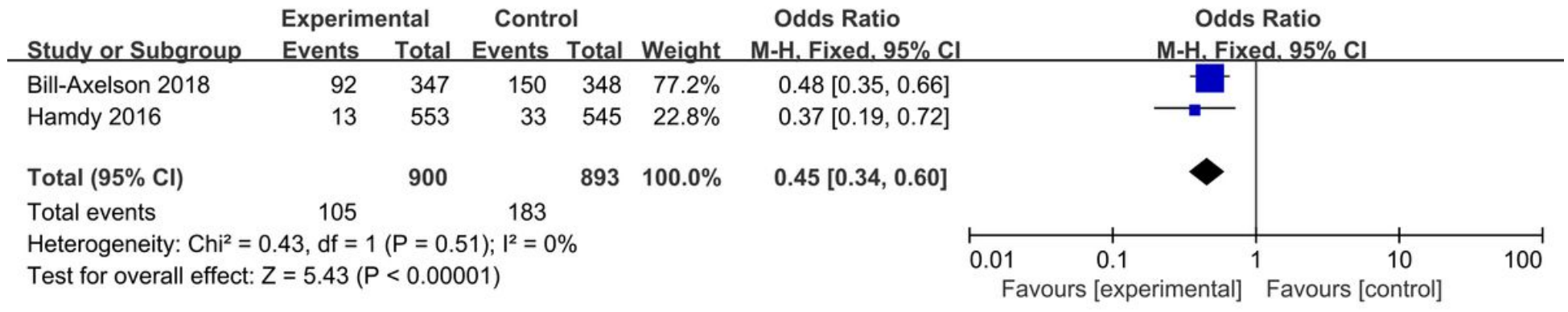

\section{Figure 3}

Meta-analysis of included studies for disease progression. 


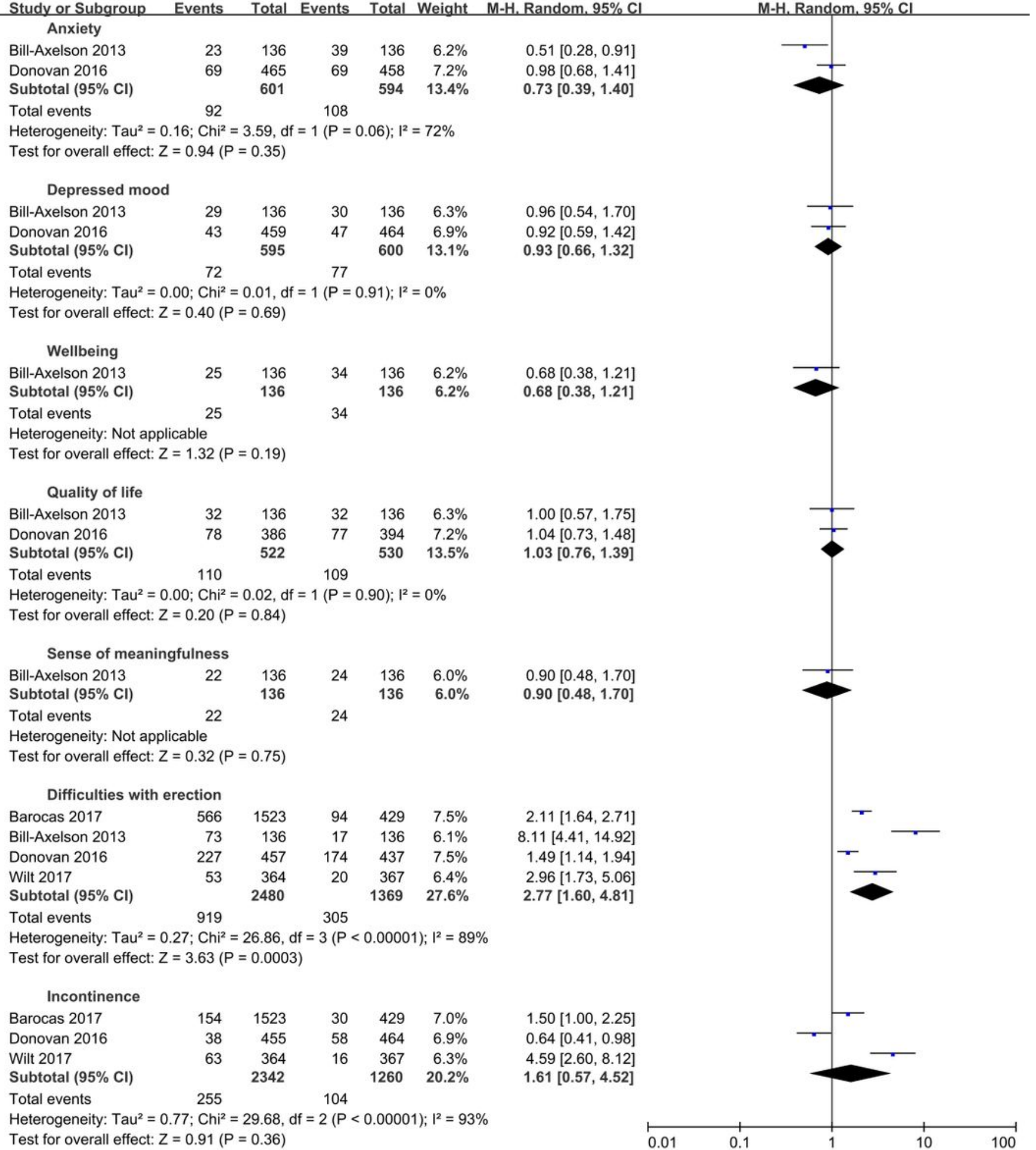

\section{Figure 4}

Meta-analysis of included studies for different symptoms. 
Begg's funnel plot with pseudo 95\% confidence limits

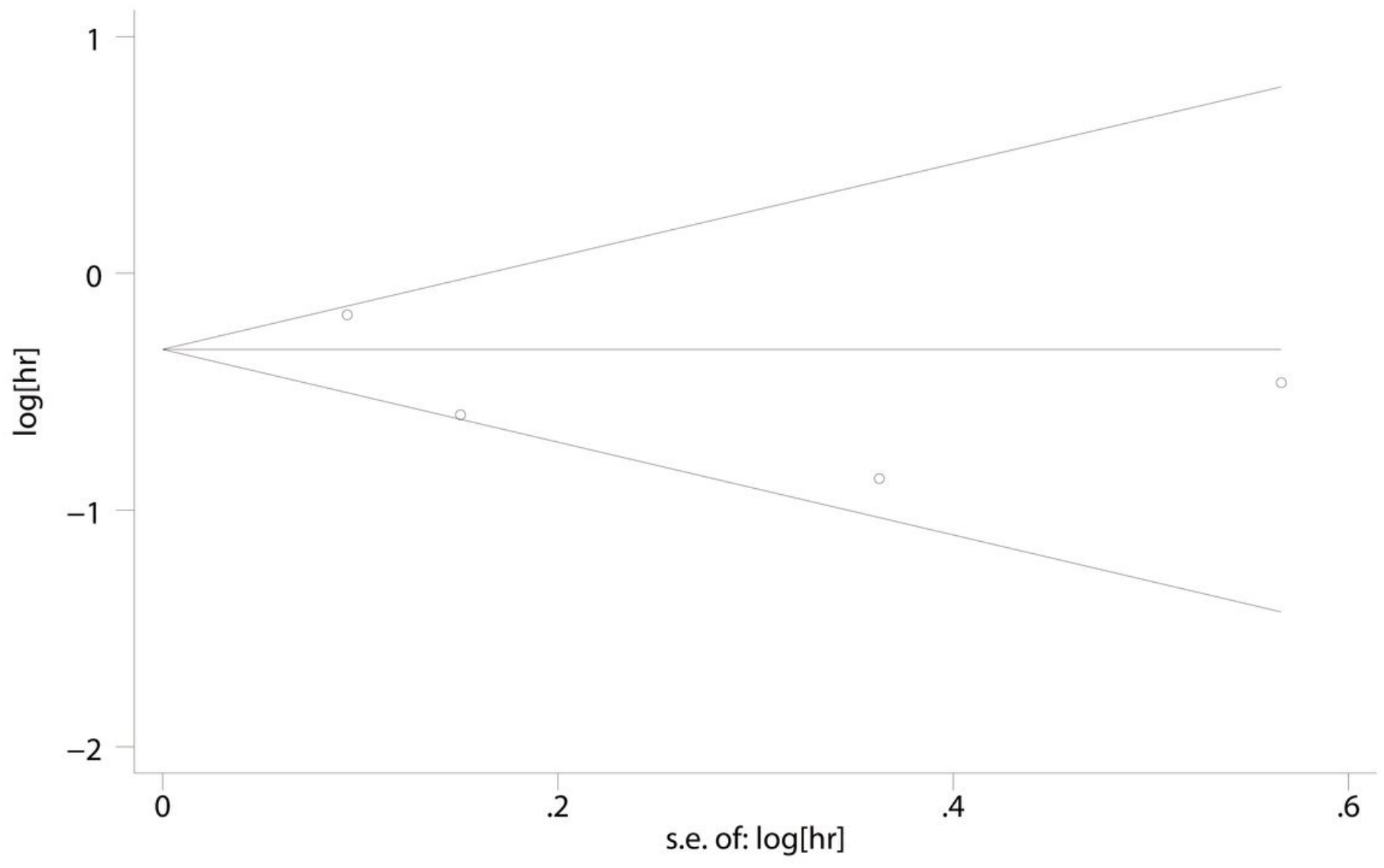

Figure 5

Funnel plots of survival analysis. 


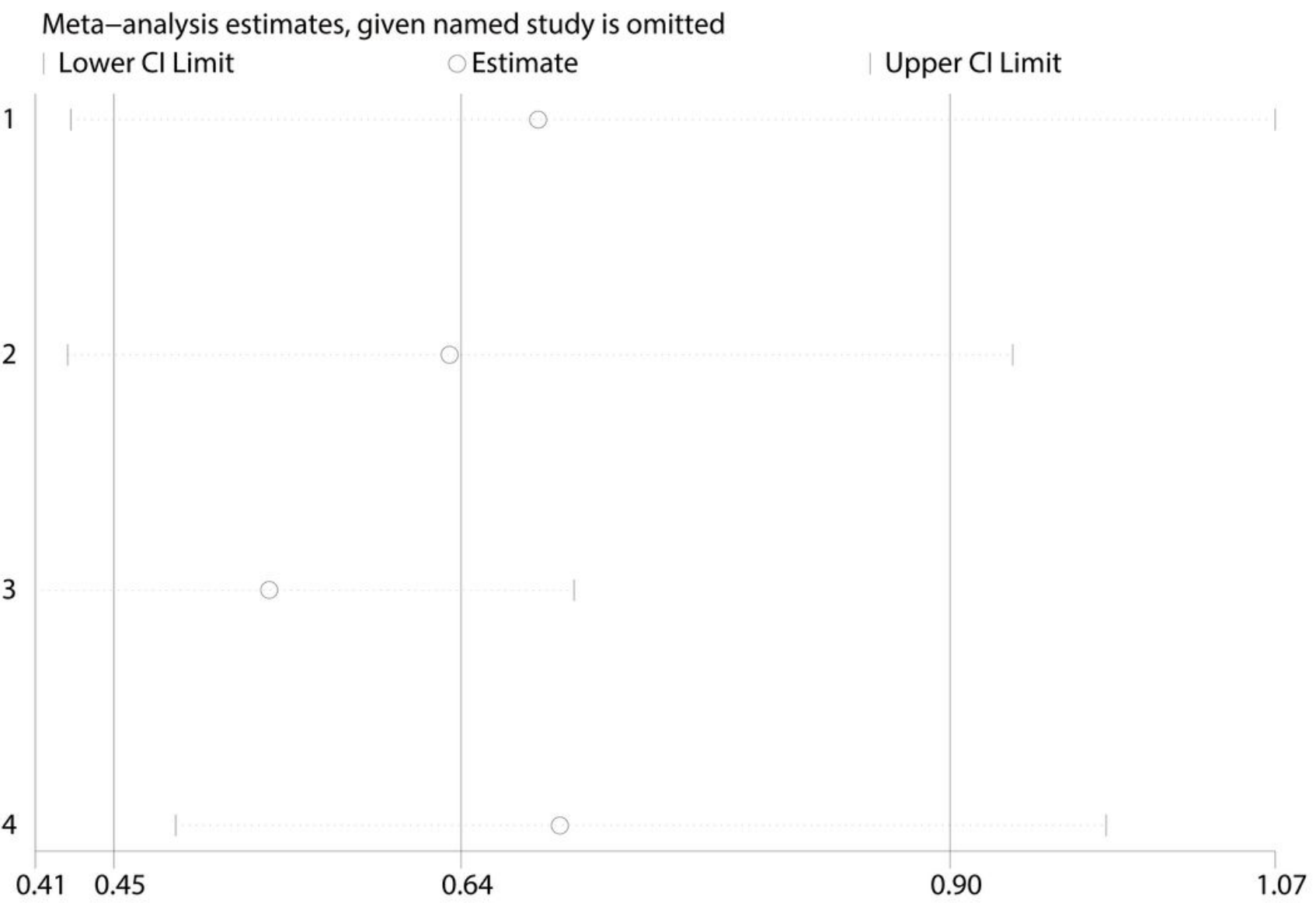

Figure 6

Sensitivity analysis of the summary OR of survival.

\section{Supplementary Files}

This is a list of supplementary files associated with this preprint. Click to download.

- supplementfigure1.jpg 